\title{
Mozzini, Camila.
}

Doctoranda en Comunicación en la Universidad del Estado de Rio de Janeiro (UERJ) y doctoranda en Arte: Producción e Investigación en la Universidad Politécnica de Valencia (UPV). Integrante de los grupos de investigación "Comunicación, Arte y Redes Sociotécnicas", "Culturas Tecnológicas: Medialidades, Materialidades, Temporalidades", en la UERJ, y del "Laboratorio de Luz" (Laboluz), en la UPV.

\section{La sobrevida de la imagen: desantropologías y el esbozo de una energética de la existencia}

\section{The survival of the image: deanthropologies and the sketch of an energetics of existence}

\author{
TIPO DE TRABAJO: \\ Comunicación. \\ PALABRAS CLAVE: \\ Historia; Aura; Walter Benjamin; Desantropología; Energética de la Existencia.
}

KEY WORDS:

History; Aura; Walter Benjamin; Deanthropologies; Energetics of Existence.

\section{RESUMEN}

Frente a los rigores del llamado "antropoceno", el presente escrito propone una epistemología desantropológica que raye el binomio humano/no-humano en pro de otras relaciones entre seres, entes y criaturas: una energética de la existencia que tome los artefactos sociales como resquicios de producción de memoria que, a través de la sobrevida de la imagen, hablan de la materialidad histórica de las fuerzas atemporales. Para ello, los conceptos de historia (BENJAMIN, 1984; HANSEN, 1998) y de aura (BENJAMIN, 1989; 2012; HANSEN, 2008) en Walter Benjamin servirán como marco teórico para repensar el estatuto de la vida humana que se inmortaliza a través de la imagen.

\section{ABSTRACT:}

Facing the rigors of the so-called "anthropocene", the present work proposes a deanthropological epistemology that scratches the binomial human/non-human in favor of other relationships between beings, entities, and creatures: an energetics of existence that regards social artifacts as vestiges of the production of memory that, through the survival of the image, speak of the historical materiality of temporal forces. To that end, the concepts of history (BENJAMIN, 1984; HANSEN, 1998) and aura (BENJAMIN, 1989; 2012; HANSEN, 2008) in Walter Benjamin will serve as a theoretical hallmark in order to rethink the statute of human life that is immortalized through the survival of the image. 


\section{CONTENIDO.}

A comenzar por la palabra "Antropología": "a" mayúscula y en el singular. Campo de conocimiento que se legitimó como disciplina científica a mediados del siglo XIX, cuando la teoría evolucionista de Darwin rompió con la versión creacionista de lo humano y lo aproximó al tiempo geológico de la naturaleza. Hijo menor de la creación, lo "humano" pasó, entonces, a ser vislumbrado como el último y desesperado esfuerzo de la madre-tierra por expeler una criatura proveniente de linajes de monos. Un giro epistemológico que tornó histórico un origen antes dado como espontáneo, provocando la emergencia de una nueva área del saber con el objetivo de investigar los rastros de tal ancestralidad tanto en términos biológicos como en los trazos culturales de sociedades denominadas "primitivas". El hecho es que, de ahora en adelante, el humano se convertiría en objeto de estudio, en foco de atención, en centro de análisis, en posibilidad de medición, en narratividad histórica. Viajes, expediciones y excursiones no faltaron en la búsqueda por vestigios materiales que rescatasen los eslabones perdidos capaces de remontar el rompecabezas de esta especie animal... Malinowski, Boas y Levi-Strauss que lo digan: nace la llamada "Antropología" con derecho a todos sus "estructuralismos".

Muchas vueltas en torno al Sol acontecieron y cambios paradigmáticos también. Cada vez más la Física Cuántica tensionaba la fijación de categorías como sujeto y objeto, insertando en esta ecuación el papel del observador en la producción de efectos de realidad. En las Humanidades, tal problemática no sería diferente. El siglo XX, especialmente la segunda mitad, está marcado por una ola de cambios y rupturas epistemológicas, tales como el "giro lingüístico" de los años 1950. En este período, una conjunción singular de fuerzas hizo con que otra relación con el lenguaje instaurase una rajadura en el pensamiento filosófico, impactando especialmente en teóricos nombrados como "post-estructuralistas", tales como Michel Foucault, Gilles Deleuze, Feliz Guattari y Jacques Derrida: en este momento, el lenguaje pasó a ver visto no apenas como un mediador neutro que habla sobre las cosas, sino como fuerza política capaz de producir realidad y efectos en el mundo. O sea: al contrario de "describir el plano de los hechos, el lenguaje, en continuidad con él, pasa también a construirlo. Y, se puede añadir que, si existe acción de los signos sobre el mundo, lo inverso es también verdadero" (TEDESCO, 2008, p. 119-120).

Un lenguaje no neutro para una realidad heterogénea. Al contrario de las búsquedas por universales que diesen cuenta de categorías explicativas del "hombre", se abre el juego de las contigencias históricas que posibilitan saberes y haceres cristalizar como verdades. La Antropología renueva su mirada a lo humano, entendiéndolo no más como un individuo social, sino como ser dividido, múltiple, arraigado en hábitos y costumbres que se constituyen históricamente en las prácticas cotidianas. Un cotidiano, por cierto, cada vez más organizado por carreteras, ladrillos, placas, legislaciones, muros, cubiertos, herramientas, fábricas, máquinas, antenas, satélites, coches, aviones, aparatos analógicos y digitales: no-humanos. Frente a tal escenario, Bruno Latour (2001) despunta en los años 1990 con la llamada "antropología simétrica": no se trata de "extender subjetividad a las cosas" o "tratar a humanos como objetos" (p. 222), sino buscar romper con el tratado modernista que purifica el conocimiento y la vida en las famosas categorías científicas de sujeto y objeto.

Para Latour, el mito del progreso se funda en la percepción de que es posible separar y aclarar, frente a los percances temporales, lo que es objetivo do lo que es subjetivo, colocando de un lado la eficiencia y de otro los valores y sentimientos. Frente a tal configuración, la alternativa lanzada por Latour es que "al contrario de esclarecer más las relaciones entre objetividad y subjetividad, el tiempo enreda en un mayor grado de intimidad y en una escala más amplia, humanos y no-humanos" (p. 229). Se instauraría entonces, tanto en el presente como en el futuro, una confusión cada vez mayor entre humanos y no-humanos a medida que se entrelazan en las llamadas "redes sociotécnicas". Sin embargo, aunque la propuesta da antropología simétrica reposicione el lugar del humano frente al considerado como no-humano, su premisa antropológica opera lingüísticamente de modo bastante peculiar: sólo es posible definir aquello que es del orden de lo "no-humano" cuando lo "humano" aún es tomado como referencia epistemológica. O sea, todo el resto que no se encaja en la forma de esta especie animal tan privilegiada entra en otra categoría genérica que todo puede abarcar. Aunque simétricamente, el par humano/no-humano produce otro modo de relación binaria a medida que toma lo humano como parámetro referencial.

Frente a las dificultades del llamado "antropoceno", o sea, de un período en que la intervención humana es tan intensa que altera y actúa como una fuerza biológica de impacto global sobre el clima y sobre el funcionamiento de los ecosistemas terrestres, el estatuto de la acción humana emerge bajo otra perspectiva. Esto porque, si pensamos en una escala de tiempo que abarque solamente la contemporaneidad, ciertamente la antropología simétrica de Bruno Latour (2001) hará todo sentido al posicionar humanos y no-humanos en un mismo estatuto ontológico. No obstante, en términos de escala geológica, nosotros, humanos, como benjamines de un largo proceso de creación, ni siquiera precisamos existir como especie - y probablemente estaremos destinados a la extinción - para que nuestro tan apreciado planeta Tierra exista como un planeta vivo. Frente a la radicalidad del vivir, nos vemos dispensables. Tal insignificancia será aquí trabajada a partir de los conceptos de historia y de aura en Benjamin: ¿no sería la hora de operar epistemológicamente en términos que puedan dar cuenta de aquello que vive en sentido lato, no necesariamente humano? ¿No sería el momento de inventariar desantropologías? En este sentido, tomaremos el pensamiento-materia de Walter Benjamin para, en él, replantear la posición de la especie humana que, mismo que destinada a la extinción, sobrevive a través de la materialidad de los resquicios culturales de la imagen. 
Contrariando corrientes hegemónicas que conciben la historia como un campo inmerso en cuestiones metafísicas o suprahistóricas, Walter Benjamin se hace eco de una perspectiva histórica que busca rasgar este velo de las apariencias, continuidades y esencias en pro de la disrupción del acaso, de lo fragmentado, "del presente como un 'ahora' en el cual se infiltraron astillas de lo mesiánico" (BENJAMIN, 1994, p. 232). Al contrario del historicismo, que "se contenta en establecer un nexo causal entre varios momentos de la historia" (BENJAMIN, 1994, p. 232), Benjamin instaura una temporalidad intensiva, no lineal, en la cual las fuerzas de la creación emergen como fuerzas de transformación y de ruptura de las premisas antropológicas que fundamentan la producción histórica:

Many of the critical and philosophical writings that belong to Benjamin's so-called metaphysical, preMarxist period, but also following his turn to historical materialism, deserve to be reinterpreted in light of an aspect of his philosophy of history that, for the most part, has been unexamined: the ethicotheological call for another kind of history, one no longer purely anthropocentric in nature or anchored only in the concerns of human subjects (HANSSEN, 1998, p. 1).

Una historia no centrada más en el sujeto humano ni en oposición a los designios de la naturaleza: es en esta interface que Benjamin articula la llamada "historia natural": "by suggesting that nature and history were 'commensurable' in the moment of transience that befell both, Benjamin's study in fact contested the idealistic dichotomy between history and necessity, human freedom and nature (HANSSEN, 1998, p. 9). Así, al contrario de algo predefinido, desde siempre allí, inmutable, pronto para ser desvelado, "naturaleza" adquiere otro estatuto ontológico: el carácter de construcción y de producción de cultura deja de ser exclusivo de la entidad "historia", ya que, en Benjamin, los fragmentos de la cultura son entendidos como fósiles naturales (BUCKMORSS, 1989), permitiendo visibilizar, en la naturaleza, las marcas de la historia. No más una naturaleza acabada, dada, origen primordial, sino imbricada en el proceso de transitoriedad y decadencia característicos de la dinámica temporal que compone el devenir histórico: "nunca hubo un monumento de la cultura que no fuese también un monumento de la barbarie" (BENJAMIN, 1994, p. 225). No por acaso, Benjamin aproxima la figura del Angelus Novus de Paul Klee y del Unmensch: el salvador no es más el honrado héroe que empuñaba la espada, sino un ser que se desfiguró de su humanidad, que se desencarnó de su condición carnal, que apareció para asombrar lo que restó de solemne al orgullo humano. Es a través de la mirada bizca y de la boca desdentada del ángel de Klee que el ángel de la historia de Benjamin emerge como alegoría de un devenir desantropológico. Un ángel que se presenta como la pesadilla de la que se hace necesario despertar: el futuro.

Hay un cuadro de Klee que se llama Angelus Novus. Representa un ángel que parece querer apartarse de algo que él encara fijamente. Sus ojos están abiertos de par en par, su boca dilatada, sus alas abiertas. El ángel de la historia debe tener este aspecto. Su rostro está dirigido hacia el pasado. Donde nosotros vemos una cadena de acontecimientos, él ve una catástrofe única, que acumula incansablemente ruina sobre ruina y las dispersa a nuestros pies. A él le gustaría detenerse para despertar a los muertos y juntar los fragmentos. Pero una tempestad sopla del paraíso y se sujeta en sus alas con tanta fuerza que él no puede cerrarlas más. Esta tempestad lo impulsa irresistiblemente para el futuro, a lo cual él da la espalda, mientras el amontonado de ruinas crece hasta el cielo. Esta tempestad es lo que llamamos progreso (BENJAMIN, 1994, p. 226).

Si la experiencia del tiempo y del espacio que produce las intensidades de la memoria se enfrenta con la inminencia del fin, plantas, piedras, casas, calles, relojes, fotografías, mosquitos, ropas, esquinas, despensas, estaciones del año, libros, animales, ángeles emergen no más como meros "objetos" o "no-humanos", sino, encima de todo, como vestigios de vida: modos de existencia. Resquicios que implican otras formas de relación con el entorno. Seres que exteriorizan y actualizan las posibilidades de recordar de sí mismo. Rastros que actúan como testigos de la historia. Objetos que absorben capas de afecto. Antes incluso de la reivindicación de una ontología simétrica entre humanos y no-humanos, tal como la protagonizada por Latour (2001), Benjamin operacionalizó tal intento en una escritura que confiere a los entes que nos cercan de otro estatuto:

Saber orientarse en una ciudad no significa mucho. No obstante, perderse en una ciudad, como alguien se pierde en una floresta, requiere instrucción. En este caso, el nombre de las calles debe sonar para aquel que se pierde como el estallido de una rama seca al ser pisada, y las callejuelas del centro de la ciudad deben reflejar las horas del día tan nítidamente como un desfiladero (BENJAMIN, 1987, p. 73). 
Equiparando calles y ramas, ciudades y florestas, callejuelas y la luz del sol, se instaura otro régimen de equivalencias entre seres, entes y criaturas: un desmantelamiento del par humano/no humano en las jerarquías y simetrías, otro prisma de equidad que redimensiona lo humano en el juego de las relaciones con lo que existe tramada a partir de una escritura del afecto, capaz de interrelacionar todo, tal como el propio concepto de aura en Benjamin: "genuine aura appears in all things, not just in certain kinds of things, as people imagine" (BENJAMIN, apud HANSEN, 2008, p. 23). Como especie de sustancia que filtra todo, envuelve y sumerge, la noción de aura emerge en su acepción no-hegemónica como un medium similar a la materialidad del éter, sustancia hipotética sin masa y sin volumen que los filósofos acreditaban ser el medio de propagación de la luz. Esto porque, al contrario de la tan cristalizada concepción de aura del ensayo $A$ obra de arte na era da reprodutibilidade técnica como "aparición única de una cosa distante, por más cerca que ella esté" (BENJAMIN, 1994, p. 170), una arqueología de otros ensayos del autor permite reposicionar la noción de aura como un medium de la percepción (HANSEN, 2008). Un medium en la medida en que el aura emerge no más como algo inherente a las cosas o una propiedad que naturalmente emana del ser, sino como un lugar de relación entre aquello que compone determinado espacio-tiempo: "the aura is a medium that envelops and physically connects and thus blurs the boundaries between subject and object, suggesting a sensory, embodied mode of perception" (p. 351).

Una concepción de historia y de historia natural que toma como piedra de toque la decadencia y trama otra relación temporal entre cultura y naturaleza. Una noción de aura como medio de relación que reconfigura las fronteras entre sujeto y objeto para más allá de la dicotomía humano y no-humano: ahí están anclados, en el pensamiento de Benjamin, los ingredientes necesarios para producir un elixir - o quizá veneno - desantropológico: una energética de la existencia. Energética en la medida en que posiciona todo y cualquier cuerpo como pasible de relación a través de un análisis material del movimiento de las fuerzas en acción en los agenciamientos entre cuerpos, sea él una piedra, un insecto, una imagen fotográfica, una proyección de película, un libro, un perfil de red social, una nave aeroespacial, un astronauta, otro planeta, una estrella, una nueva sustancia en la tabla periódica, una partícula subatómica, una vida cualquiera, incluso, la humana. De la existencia porque, al contrario de un substituto directo de la palabra "vida", la noción de "existencia" está más allá de la muerte: incluso cuando se muere, se continúa existiendo. Existir no solamente por el modo como se vive, sino, sobre todo, por el modo como se es recordado. Ser recordado en la memoria de los cuerpos, de los afectos, de las cartas, de los billetes guardados, de los periódicos, de los emails, de las pinturas, de los retratos, de las películas, de las canciones, de las performances, de los perfiles en redes sociales, de los bancos de datos, de los rastros digitales, de las cajas-negras, de las cámaras de vigilancia. Tal como Benjamin experimentaba una relación íntima con su entorno, un existir en la memoria de cualquier modalidad material que viniese a inscribirse. Energética de la existencia en la medida en que busca tomar los artefactos sociales como resquicios de producción de memoria que, a través de la sobrevenida imagen, hablan de la materialidad histórica de las fuerzas atemporales.

Si etimológicamente, la palabra "energía", del griego ergos, significa trabajo, una energética de la existencia permite hablar del trabajo, o sea, de la acción, reacción, deformación y transformación de los cuerpos unos sobre otros frente a su condición transversalizada, tramada, enredada, tejida en conjunto: un inmenso campo de fuerzas capaz de crear relaciones entre todo lo que hay - un inmenso fluido invisible que conecta todo, tal como la noción de aura como medium. Un campo necesariamente histórico que habla no sólo de la condición humana, sino, sobre todo, de las condiciones de producción y de reproducción de todo lo que es y fue vivo. Un campo que, en el contemporáneo, tensa al vivir, un existir: seres muertos con perfiles en la red social Facebook que resisten otro ciclo biológico a partir de complejos agenciamientos algorítmicos, eléctricos y humanos. Fósiles naturales en los fragmentos de la cultura: seres que, en el rastro de un cuerpo-carne que se fue y en la permanencia de un cuerpo-algoritmo que se actualiza como lenguaje de programación informática, crean sujetos alimentados no más por oxígeno y comida, sino por la fuerza de la electricidad que, en este cruzamiento, componen un cuerpo-imagen en la superficie de la pantalla. Una energética de la existencia que se actualiza en el ímpetu de proyectar lo humano para más allá de la esfera terrestre a través de la producción cultural de imágenes, tal cual el proyecto Mars One ${ }^{1}$.

Con el objetivo de instaurar la vida humana en Marte en el año 2023, la empresa privada recluta de entre millares de candidaturas, aquellos que están dispuestos a abrirse a otra sensorialidad: "Usted nunca más sentirá el viento batiendo en su cabello, usted nunca más oirá el sonido de caminar por la nieve, usted no oirá el canto de los pájaros allí fuera. Si usted realmente se importa mucho con estas cosas, no debería candidatarse para una misión a Marte" - dice Bas Lansdorp, cofundador de la expedición. Esto porque el viaje prevé un billete solamente de ida teniendo en vista no haber tecnología suficiente para producir la vuelta. ¿Y cómo

\footnotetext{
${ }^{1}$ El proyecto oficial de MarsOne puede ser visualizado en los links: https://www.youtube.com/watch?v=7gV7LX0tLDw, https://www.youtube.com/watch?v=n4tgkyUBkbY. Acceso en 28/062/2017, a las $20 \mathrm{h03}$.
} 
será realizada la financiación de esta enorme epopeya? "Nosotros financiaremos esta misión creando el mayor evento de medios de comunicación ya visto. Todo el mundo podrá ver todo lo que acontecerá en la preparación y en Marte", cuenta Bas, complementado por Gerard 'T Hooft, físico ganador del premio Nobel: "Esto será un espectáculo mediático, Big Brother se apagará en comparación". O sea, a través de muchos y muchos aparatos técnicos que materializan la ubicuidad de la imagen, se pretende viabilizar tal episodio como un evento mediático vía redes de visualización digitales: imágenes que no sólo funcionan como condición financiera para la concretización del proyecto, sino que también concretizan la presencia de la vida humana a través de la existencia de la imagen.

¿Un mundo mejor y más feliz? Al contrario de un nuevo Edén, sus implicaciones son múltiples y nebulosas: al mismo tiempo en que emergen otros regímenes de producción sensible, formas cada vez más sofisticadas de captura de las prácticas para fines de mercado se utilizan de la rastreabilidad de lo digital y de la fascinación de la imagen para crear relaciones más imbricadas entre consumo, imagen, cuerpo y experiencia. Es de este caldero de posibilidades de juegos entre humanos, animales, plantas, sustancias y de todo aquello que está vivo a partir de una reordenación de lo sensible que la noción de "energética de la existencia" propone crear sistemas de simetría para más allá de lo humano - lo que no significa sin humano, sino un humano desplazado: desplazado de su centralidad analítica, de su premisa antropomórfica, de su categorización referenciada a sí mismo. Un humano que abandona su planeta en decadencia y se proyecta en dirección al espacio intergaláctico. Un humano que se ve vulnerable en medio a un mundo de objetos necesarios para iniciar su jornada universo afuera. Un humano que se vale de la umbilical relación con la humanidad de las máquinas para ir al encuentro de aquello que le torna otro, extraño a sí mismo, no más "humano" ni "no-humano", sino un ser en relación con otros seres: un humano inmortalizado por la sobrevenida de la imagen.

\section{FUENTES REFERENCIALES.}

BENJAMIN, Walter. Rua de mão única - Obras escolhidas, volume 2. Rubens Rodrigues Torres Filho; José Carlos Martins Barbosa (trads.). São Paulo: Brasiliense, 1987.

Teses sobre o conceito de história. In: Walter Benjamin - Obras escolhidas. Vol. 1. Magia e técnica, arte e política. Ensaios sobre literatura e história da cultura. Sérgio Paulo Rouanet (trad.). São Paulo: Brasiliense, 1994.

A obra de arte na era da sua reprodutibilidade técnica. In: Tadeu Capistrano (Org.), Benjamim e a obra de arte: técnica, imagem e percepção. Tradução Marijane Lisboa e Vera Ribeiro. Rio de Janeiro: Contraponto: 2012.

BUCK-MORSS, Susan. The Dialectics of Seeing: Walter Benjamin and the Arcades project. United States of America: The Halliday Lithograph, 1989.

CHARLES, Matthew. Walter Benjamin and the inhumanities: toward a pedagogical anti-nietzscheanism In: Pegagogies of Disaster. Vincent W. J. van Gerven Oei; Adam Staley; Nico Jenkings (orgs.). Punctum Books, NY; The Department of Eagles, Tirana, Albania: 2013, p 331-341.

FOUCAULT, Michel. A coragem da verdade. Eduardo Brandão (trad). São Paulo: Martins Fontes, 2011.

HANSEN, Miriam Bratu. Benjamin's Aura. In: Critical Inquiry. Winter, 2008.

HANSSEN, Beatrice. Walter Benjamin's other History: of Stones, Animals, Human Beings, and Angels. Berkeley: University of California Press, 1998.

LATOUR, Bruno. A esperança de Pandora. Bauru: Edusc, 2001.

TEDESCO, Silvia. Políticas da cognição. Porto Alegre: Sulina, 2008, p. 113-135. 